\title{
Efficacy of orysastrobin against blast and sheath blight in transplanted rice
}

\author{
Gerd Stammler, ${ }^{*}$ Manabu Itoh, ${ }^{\dagger}$ Isao Hino, ${ }^{\dagger}$ Akihide Watanabe, ${ }^{\dagger \dagger}$ Kenichi KoJima,${ }^{\dagger \dagger}$ \\ Masatoshi Motoyoshi, ${ }^{\dagger \dagger}$ Andreas Koch and Egon HadeN \\ BASF Aktiengesellschaft, 67114 Limburgerhof, Germany \\ ${ }^{\dagger}$ BASF Agro Ltd., Roppongi, Minato-ku, Tokyo, 106-0032, Japan \\ ${ }^{\dagger}$ BASF Agro Ltd., Kamigaya, Mutsure, Tahara, Aichi, 441-3413, Japan
}

(Received July 10, 2006; Accepted October 19, 2006)

\begin{abstract}
Orysastrobin is a new QoI fungicide with excellent fungicidal efficacy against leaf and panicle blast and against sheath blight in rice. Formulations developed for seedling box treatments provide long lasting residual control combined with excellent plant selectivity under different environmental conditions. The sensitivity was monitored based on genetic assays. No samples with reduced sensitivity could be detected in our extensive monitoring studies in 2004 and 2005. (C) Pesticide Science Society of Japan
\end{abstract}

Keywords: orysastrobin, blast, sheath blight, pyrosequencing, Magnaporthe grisea, Thanatephorus cucumeris.

\section{Introduction}

Orysastrobin, (2E)2-(methoxyimino)-2-\{2-[(3E,5E,6E)-5(methoxyimino)-4,6-dimethyl-2,8-dioxa,7-diazinona-3,6dien-1-yl]phenyl $-N$-methylacetamide, is the common name of a new QoI fungicide discovered and developed by BASF for the control of leaf and panicle blast (Magnaporthe grisea) and sheath blight (Thanatephorus cucumeris) in rice. Its biochemical mode of action is inhibition of the mitochondrial respiration chain by binding to the cytochrome $b c_{1}$ complex at the Qo site. ${ }^{1)}$

Rice blast and sheath blight control in transplanted rice in Japan is mainly based on granule application in the seedling box. For this application type it is essential that the fungicide is safe for rice seedlings and shows long-lasting activity in the upper parts of the plant. Special granular formulations with orysastrobin have been developed for controlled release in seedling box application with or without an insecticide partner. The resulting outstanding long-lasting efficacy of orysastrobin in the field against leaf and panicle blast, and sheath blight under different conditions is here described.

Two mutations have been detected in the cytochrome $b$ gene in several plant pathogens, which govern resistance to

\footnotetext{
* To whom correspondence should be addressed.

E-mail: gerd.stammler@basf.com

Published online November 30, 2006

(C) Pesticide Science Society of Japan
}

QoI fungicides. One mutation leads to a substitution of glycine by alanine at codon 143 (found e.g. in Blumeria graminis, Mycosphaerella graminicola, Plasmopara viticola) and is the main mechanism of resistance to QoIs. ${ }^{2-4)}$ Another mutation at codon 129 (found e.g. in Pyrenophora teres, Alternaria solani), which leads to the substitution of phenylalanine by leucine results in lower resistance factors. ${ }^{5,6)}$ A monitoring program based on genetic analysis of the cytochrome $b$ gene has been established, and the methods and data are reported.

\section{Material and Methods}

\section{Chemicals}

The chemical structure of orysastrobin is shown in Fig. 1. Orysastrobin was used in granular formulations containing $7 \%$ orysastrobin with or without insecticide partners. Efficacy

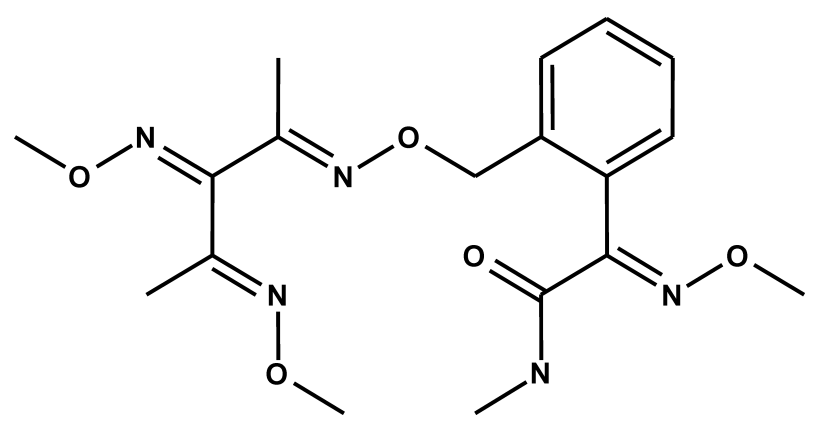

Fig. 1. Chemical structure of orysastrobin. 
against rice blast was compared with commercial available granular products for seedling box application containing 3\% diclocymet, $24 \%$ probenazole or $12 \%$ pyroquilon. Controlling activity against rice sheath blight was compared with seedling box granular products containing $4 \%$ furametpyr or $3 \%$ thifluzamide.

\section{Field trials}

\subsection{Application and transplanting}

Fungicides were applied as granular formulations to seedling boxes. Each fungicide $(50 \mathrm{~g})$ was scattered in each seedling box $(30 \times 60 \mathrm{~cm})$, corresponding to $10 \mathrm{~kg}$ product/ha. Applications were made on the day of transplanting. For trials investigating the influence of application timing on selectivity and efficacy, applications were done at the seeding stage (after seeding, before soil covering), at the greening stage (2 days after emergence) and on the day of transplanting.

\subsection{Trial layout}

Seedlings were transplanted into paddy fields using a commercial mechanical transplanter (Kubota, two rows). Trials were performed in 2002 and 2003 at different trial sites in Japan. In each trial, three randomised replicates per treatment were used with a minimum plot size of $15 \mathrm{~m}^{2}$. The cultivation of the crop was according to normal practical standards. The rice variety used was Koshihikari.

\subsection{Evaluation of disease}

Leaf blast was evaluated at growth stage 24-34, which corresponds to 48-64 days after transplanting. Panicle blast was evaluated at growth stage 77-85, which corresponds to 85103 days after transplanting. Leaf blast was assessed by estimating the infected leaf area in \%, panicle blast by using the damage index calculation $\operatorname{method}^{7}$ (damage index $=$ $\mathrm{A}+0.66 \mathrm{~B}+0.26 \mathrm{C}, \mathrm{A}=\%$ panicles attacked at panicle neck, $\mathrm{B}=\%$ of panicles whose rachis area is damaged by $>1 / 3$, $\mathrm{C}=\%$ of panicles whose rachis area is damaged by $<$ or $=1 / 3$ ). Sheath blight was assessed at growth stage 77-87 (86-106 days after transplanting) using the Hashiba method ${ }^{8)}$ (Total damage index $=\mathrm{A} \times \%$ infected hills/100; $\mathrm{A}$, index of attacked hill $=1.62 \times \mathrm{B}-32.4 ; \mathrm{B}=$ lesion height $/$ plant height $\times 100 \%$ ).

2.4. Statistical analysis

Statistical analyses were performed with SAS. The Student-Newman Keuls test, $(P<0.05)$ was used for comparisons of disease severity. Percentage disease values were arcsin-square-root transformed.

\section{Sensitivity monitoring}

\subsection{Sampling preparation}

Leaves or panicles diseased with Magnaporthe grisea were collected from different sites of commercial fields or trial sites in 2004 and 2005. At trial sites, samples were taken from plots treated with orysastrobin, reference products or from untreated plots. In total, 216 samples were analysed in 2004 and 135 samples in 2005. In the samples, lesions were cut out from the leaves or diseased panicles were selected. These parts were dried and then homogenised by milling after freezing in liquid nitrogen with a MixerMill MM200 (Retsch, Hahn, Germany).

\subsection{DNA isolation and PCR amplification}

Total DNA was extracted using the DNA NucleoSpin Plant Extraction Kit (Macherey and Nagel, Düren, Germany) and suspended in $50 \mu 1 \mathrm{H}_{2} \mathrm{O}$. PCR was carried out with $5 \mu \mathrm{l}$ DNA solution, $1 \mu \mathrm{l}$ dNTP's $(10 \mathrm{mM}), 2.5 \mu \mathrm{l}$ of forward primer and reverse primer $(10 \mathrm{pmol} / \mu \mathrm{l}), 5 \mu \mathrm{l} 10 \times$ ThermoStart buffer (Abgene, Hamburg, Germany) and $0.5 \mu 1$ ThermoStart DNA Polymerase (Abgene). The sequences used were for the forward primer: 5'-TGGAAGCTTTTAACTCAATAGAG-3' and the reverse primer: 5' Biotin-TGCCCTATTCAAGGTATAGCA-3'. PCR was performed on a Mastercycler Gradient (Eppendorf, Hamburg, Germany). PCR amplifications were carried out using the following parameters: Initial preheating for $15 \mathrm{~min}$ at $95^{\circ} \mathrm{C}$, followed by 50 cycles at $95^{\circ} \mathrm{C}$ for $15 \mathrm{~s}, 60^{\circ} \mathrm{C}$ for $30 \mathrm{~s}$ and $72^{\circ} \mathrm{C}$ for $30 \mathrm{~s}$ and a final amplification step at $72^{\circ} \mathrm{C}$ for $5 \mathrm{~min}$. The length of the PCR product was $301 \mathrm{bp}$. For control of the PCR amplification, an aliquot of the PCR product was separated on a $2 \%$ agarose gel, stained with ethidium bromide and visualized with UV light.

\subsection{Pyrosequencing}

PCR products were used for further sequence analysis. Single nucleotide polymorphisms in the codons for amino acid 129 and amino acid 143 were analysed using the pyrosequencing method, as previously described ${ }^{9,10)}$ and according to the instructions by the manufacturer using PyroGold reagents and a PSQ 96 MA machine (Biotage, Uppsala, Sweden). The sequence primers used were for codon $1295^{\prime}$-AATATTAATGATGGCTATCG-3' and for codon 143 5' - GGACAGATGTCATTATGAG-3'. The denaturation step before sequencing was done at $75^{\circ} \mathrm{C}$ for $3 \mathrm{~min}$ and the whole sequencing procedure was carried out at $28^{\circ} \mathrm{C}$. Sequence data were analysed quantitatively using software provided by the manufacturer (Biotage).

\section{Results}

\section{Efficacy against leaf and panicle blast}

In all field trials orysastrobin provided excellent control of leaf blast (Table 1) and panicle blast (Table 2) with outstanding long-lasting activity. The efficacy was equal or superior to the standard products under different disease pressure. Trials with different application timing (seeding, greening, transplanting) also showed excellent efficacy of orysastrobin against leaf and panicle blast (Table 3) independent of the application timing.

\section{Efficacy against sheath blight}

Excellent control of sheath blight was achieved by orysastrobin and this efficacy was comparable to standard sheath blight products such as thifluzamide or furametpyr under different disease pressure (Tables 4 and 5). As for blast control, 
Table 1. Efficacy of orysastrobin-containing products on leaf blast in comparison to commercialised standard products

\begin{tabular}{|c|c|c|c|}
\hline Product & $\begin{array}{l}\text { Rate fungicide } \\
\text { [g a.i./ha] }\end{array}$ & $\begin{array}{c}\% \text { Control } \\
5.0 \% \text { in untreated } *\end{array}$ & $\begin{array}{c}\% \text { Control } \\
14.3 \% \text { in untreated } *\end{array}$ \\
\hline Orysastrobin GR & 700 & $99^{c}$ & $98^{a}$ \\
\hline Orysastrobin + Fipronil GR & 700 & $99^{c}$ & $98^{a}$ \\
\hline Orysastrobin + Clothianidin GR & 700 & $99^{c}$ & $99^{a}$ \\
\hline Diclocymet combination GR & 300 & $94^{b}$ & $95^{a}$ \\
\hline Probenazole combination GR & 2400 & $99^{c}$ & $95^{a}$ \\
\hline Pyroquilon combination GR & 1200 & $91^{a}$ & $98^{a}$ \\
\hline Trial location & & Tahara, Aichi & Toyohashi, Aichi \\
\hline Year & & 2002 & 2002 \\
\hline
\end{tabular}

* Evaluation method: Diseased leaf area. Means followed by the same letter do not significantly differ (Student-Newman Keuls test, $P<0.05)$.

Table 2. Efficacy of orysastrobin-containing products on panicle blast in comparison to commercialised standard products

\begin{tabular}{|c|c|c|c|}
\hline Product & $\begin{array}{c}\text { Rate fungicide } \\
\text { [g a.i./ha] }\end{array}$ & $\begin{array}{c}\% \text { Control } \\
3.0 \% \text { in untreated } *\end{array}$ & $\begin{array}{c}\% \text { Control } \\
12.5 \% \text { in untreated }\end{array}$ \\
\hline Orysastrobin GR & 700 & $92^{a}$ & $97^{c}$ \\
\hline Orysastrobin+Fipronil GR & 700 & $94^{a}$ & $97^{c}$ \\
\hline Orysastrobin+Clothianidin GR & 700 & $91^{a}$ & $98^{c}$ \\
\hline Diclocymet combination GR & 300 & $80^{a}$ & $90^{b}$ \\
\hline Probenazole combination GR & 2400 & $67^{a}$ & $79^{a}$ \\
\hline Pyroquilon combination GR & 1200 & $67^{a}$ & $81^{a}$ \\
\hline Trial location & & Tahara, Aichi & Toyohashi, Aichi \\
\hline Year & & 2002 & 2002 \\
\hline
\end{tabular}

* Evaluation method: Diseased leaf area. Means followed by the same letter do not significantly differ (Student-Newman Keuls test, $P<0.05)$.

Table 3. Influence of the application timing of orysastrobin on the control of leaf and panicle blast in comparison to commercialised standard product

\begin{tabular}{|c|c|c|c|}
\hline \multirow{3}{*}{ Product } & \multirow{3}{*}{ Application timing } & Leaf blast & Panicle blast \\
\hline & & $\%$ Control & $\%$ Control \\
\hline & & $3.0 \%$ in untreated $*$ & $4.2 \%$ in untreated $* *$ \\
\hline \multirow[t]{3}{*}{ Orysastrobin + Fipronil GR (700 g a.i./ha) } & seeding & $97^{b}$ & $97^{a}$ \\
\hline & greening & $96^{b}$ & $94^{a}$ \\
\hline & transplanting & $96^{b}$ & $96^{a}$ \\
\hline \multirow[t]{3}{*}{ Diclocymet combination GR ( $300 \mathrm{~g}$ a.i./ha) } & seeding & $83^{a}$ & $82^{a}$ \\
\hline & greening & $87^{a}$ & $79^{a}$ \\
\hline & transplanting & $84^{a}$ & $77^{a}$ \\
\hline Trial location & & Tahara, Aichi & Tahara, Aichi \\
\hline Year & & 2003 & 2003 \\
\hline
\end{tabular}

* Evaluation method: Diseased leaf area. **Evaluation method: Panicle damage index. Means followed by the same letter do not significantly differ (Student-Newman Keuls test, $P<0.05$ ). 
Table 4. Efficacy of orysastrobin-containing products on sheath blight in comparison to commercialised standard product

\begin{tabular}{|c|c|c|c|}
\hline Product & $\begin{array}{c}\text { Rate fungicide } \\
\text { [g a.i./ha] }\end{array}$ & $\begin{array}{c}\% \text { Control } \\
7.0 \% \text { in untreated } *\end{array}$ & $\begin{array}{c}\% \text { Control } \\
40.2 \% \text { in untreated* }\end{array}$ \\
\hline Orysastrobin GR & 700 & $95^{b}$ & $89^{a}$ \\
\hline Orysastrobin+Fipronil GR & 700 & $99^{b}$ & $90^{a}$ \\
\hline Orysastrobin +Clothianidin GR & 700 & $97^{b}$ & $84^{a}$ \\
\hline Thifluzamide combination GR & 300 & $52^{a}$ & $85^{a}$ \\
\hline Trial location & & Toyohashi, Aichi & Tahara, Aichi \\
\hline Year & & 2002 & 2002 \\
\hline
\end{tabular}

this efficacy was also independent of the application time point in the seedling box (seeding, greening, transplanting, Table 5).

\section{Sensitivity monitoring}

From most samples, sufficient DNA from $M$. grisea could be isolated for amplification of sufficient PCR product in one step for sequence analysis by pyrosequencing. Only from three samples with very weak blast symptoms in 2005 was no specific amplification of the cytochrome $b$ sequence of $M$. grisea possible. All samples from plots treated with orysastrobin-containing products or products with other modes of action or untreated plots gave a full sensitivity picture in 2004 $(n=216)$ and in $2005(n=135)$. No F129L or G143A mutation in the cytochrome $b$ gene could be detected in any sample described in Table 6. In all samples, the sequence of the

Table 5. Influence of the application timing of orysastrobin on the control of sheath blight in comparison to commercialised standard product

\begin{tabular}{|c|c|c|}
\hline Product & $\begin{array}{l}\text { Application } \\
\text { timing }\end{array}$ & $\begin{array}{c}\text { Sheath blight } \\
\% \text { Control } \\
6.5 \% \text { in } \\
\text { untreated* }\end{array}$ \\
\hline $\begin{array}{l}\text { Orysastrobin + Fipronil GR } \\
\quad(700 \mathrm{~g} \text { a.i./ha) }\end{array}$ & $\begin{array}{l}\text { seeding } \\
\text { greening } \\
\text { transplanting }\end{array}$ & $\begin{array}{r}100^{a} \\
100^{a} \\
98^{a}\end{array}$ \\
\hline $\begin{array}{l}\text { Furametpyr combination GR } \\
\qquad(400 \mathrm{~g} \text { a.i./ha })\end{array}$ & transplanting & $98^{a}$ \\
\hline Trial location & & Tahara, Aichi \\
\hline Year & & 2003 \\
\hline
\end{tabular}

* Evaluation method: Hashiba damage index. Means followed by the same letter do not significantly differ (Student-Newman Keuls test, $P<0.05)$. wild-type codon (for codon 129 TTC, coding for phenylalanine and for codon 143 GGT, coding for glycine) was identified.

\section{Discussion}

The development of the fungicide orysastrobin started in the late 1990s. For the seedling box application type a granular formulation with a time-released control was formulated. The combination of high intrinsic and systemic fungicidal activity with controlled release in a granular formulation is fundamental for the excellent and long-lasting control of leaf and panicle blast, and sheath blight. For seedling box products it is mandatory that the compounds are not phytotoxic to sensitive rice seedlings. Orysastrobin is a selective compound that caused no damage through the growth stages of all tested varieties of rice (Japonica and Indica varieties). Selectivity was tested on several Japonica and Indica varieties of rice, e.g. Koshihikari, Hinohikari, Hitomebore, Akitakomachi, Haenuki and others in Japan, Tainong 67, Taigeng 16 and others in Taiwan, IR50 and IR72 in the Philippines, IAC165, Metica-1 and others in Brazil, Balilla and Lemont, and others in Europe and US. The efficacy of orysastrobin against target pathogens has been tested for 10 years in numerous trials under different environmental conditions. Orysastrobin-containing products were competitive with the best standard products for leaf blast, panicle blast (e.g. SAR compounds, melanin biosynthesis inhibitors) and sheath blight (e.g. carboxanilides). The long-lasting and high efficacy against target diseases enables farmers to save additional field applications during the vegetation period and therefore results in a reduction of labor and costs.

New modes of action in the application strategy improved the efficiency of disease management since new modes of action are effective tools to manage the development of fungicide resistance. In this sense, orysastrobin can also be useful to reduce or slow down the distribution of resistance to melanin biosynthesis inhibitors (MBI-D-type) such as carpropamid or diclocymet. 
Table 6. Origin of the samples collected for sensitivity monitoring of Magnaporthe grisea in 2004 and 2005

\begin{tabular}{|c|c|c|}
\hline Number of samples & 2004 & 2005 \\
\hline Aichi & 9 & 6 \\
\hline Akita & 9 & 2 \\
\hline Aomori & 2 & 2 \\
\hline Ehime & 0 & 8 \\
\hline Fukui & 6 & 0 \\
\hline Fukuoka & 12 & 0 \\
\hline Fukushima & 4 & 9 \\
\hline Gifu & 0 & 1 \\
\hline Gunma & 3 & 1 \\
\hline Hiroshima & 8 & 3 \\
\hline Hyogo & 22 & 1 \\
\hline Ibaraki & 8 & 8 \\
\hline Iwate & 7 & 2 \\
\hline Kagoshima & 3 & 4 \\
\hline Kochi & 6 & 8 \\
\hline Kumamoto & 5 & 4 \\
\hline Kyoto & 0 & 1 \\
\hline Mie & 3 & 0 \\
\hline Miyagi & 3 & 4 \\
\hline Nagano & 7 & 17 \\
\hline Niigata & 11 & 2 \\
\hline Oita & 11 & 1 \\
\hline Okayama & 3 & 3 \\
\hline Saga & 6 & 4 \\
\hline Shimane & 0 & 1 \\
\hline Shizuoka & 8 & 1 \\
\hline Tochigi & 5 & 5 \\
\hline Tokushima & 11 & 0 \\
\hline Tottori & 34 & 8 \\
\hline Yamagata & 7 & 29 \\
\hline Yamaguchi & 3 & 0 \\
\hline Leaf blast & 195 & 73 \\
\hline Panicle blast & 21 & 62 \\
\hline Commercial sites & 81 & 48 \\
\hline Trial sites (treated with orysastrobin) & $135(62)$ & $87(42)$ \\
\hline Total & 216 & 135 \\
\hline
\end{tabular}

To maintain the excellent activity of orysastrobin, resistance management strategies have been developed. Non-chemical control methods e.g. crop culture according to good agricultural practice (e.g. cultivation of rice varieties with less susceptibility to blast, usage of healthy seeds) are efficient tools for a significant reduction of infection pressure and are therefore appropriate to reduce selection pressure in subsequent fungicidal treatments. Additionally, the number of QoI applications per season should be restricted and other modes of action should be implemented in a season-long disease control strategy. For sustainable and responsible resistance management, monitoring of fungicide sensitivity is essential. The sensitivity status of $M$. grisea was monitored yearly during the season (leaf blast symptoms) and at the end of the season (leaf and panicle blast symptoms). Different methods were established to monitor sensitivity. In vivo assays (e.g. greenhouse trials with rice seedlings) and in vitro methods (e.g. microtiter assays) are appropriate to determine the sensitivity of isolates and ED values can be calculated. ${ }^{11)}$ Intensive studies by BASF showed a stable and narrow distribution of sensitivity (determined as $\mathrm{ED}_{50}$ values) in $M$. grisea towards orysastrobin in microtiter assays over the years (data not shown). A disadvantage of both methods is the necessity of isolating viable strains from blast lesions, which is often not possible, since in some samples no viable spores or mycelia can be found. Furthermore, a high number of strains must be isolated and tested to detect less sensitive isolates in populations with a low frequency of resistance. Since the genetic background of QoI resistance is clearly understood, a genetic approach for resistance monitoring is possible. Several methods based on DNA analysis are possible and for all these methods no living material is necessary. Codons of the cytochrome $b$ gene, which must be included in genetic analysis, are 129 and 143. The relevant mutations F129L and G143A are caused by single nucleotide exchanges. For F129L, three different codons are possible for leucine (CTC, TTA, TTG) with one nucleotide exchange from the wild-type phenylalanine codon (TTC), and all three mutated codons have been found in Pyrenophora teres in Europe (own unpublished data). For G143A, only one codon for alanine (GCT) is possible with one nucleotide exchange from the wild-type glycine codon (GGT). Qualitative PCR assays as described by Araki et $a{ }^{12)}$ (amplification of the cytochrome $b$ gene followed by subsequent digestion with a specific restriction enzyme) are appropriate for determination of the G143A mutation if the restriction enzyme SatI is used. Detection of the F129L mutation by qualitative PCR using StyI as a restriction enzyme can lead to false negative data, since only the leucine codons TTG and TTA, but not the leucine codon CTC show a different restriction pattern to the wild-type phenylalanine codon (TTC).

Quantitative real-time PCR based on the amplification refractory mutation system (ARMS) ${ }^{13)}$ provides a sensitive method for the detection of single mutations. For G143A it is an appropriate method, but for F129L it would be more labor and cost intensive because of the different codons possible for this exchange. In this case, detailed information on the whole sequence of codon 129 is needed and the pyrosequencing method represents an efficient quantitative one-step method to achieve this. Because of synergistic effects in the analysis 
procedure, this method was used for the quantitative monitoring of both mutations, F129L and G143A.

No QoI-resistant isolate of $M$. grisea from rice could be detected in our extensive monitoring studies in 2004 and 2005. The data show the full QoI sensitive situation throughout Japan.

\section{Acknowledgements}

The authors wish to thank Sumika-Takeda, Nissan and Kyoyu Agri for providing samples for monitoring studies.

\section{References}

1) H. Sauter, W. Steglich and T. Anke: Angew. Chem. Int. Ed. 38, 1328-1349 (1999).

2) S. P. Heaney, A. A. Hall, S. A. Davies and G. Olaya: "The BCPC Conference Pests and Diseases, 2000," The British Crop Protection Council, Alton, Hampshire, UK, pp. 755-762, 2000.

3) I. Yamaguchi and M. Fujimura: J. Pestic. Sci. 30, 67-74 (2005).

4) I. Ishii, B. Fraaije, T. Sugiyama, K. Noguchi, K. Nishimura, T. Takeda, T. Amano and D.W. Hollomon: Phytopathology 91,
1166-1171 (2001).

5) Y. Kim, E. W. Dixon, P. Vincelli and M. L. Farman: Phytopathology 93, 891-900 (2003).

6) J. S. Pasche, C. M. Wharam and N. C. Gudmestad: "The BCPC Conference Pests and Diseases, 2002," The British Crop Protection Council, Alton, Hampshire, UK, pp. 841-846, 2002.

7) H. Suzuki: JPPA (Japan Plant Protection Association), 52, (1990).

8) T. Hashiba: Bull. Hokuriku Natl. Agric. Exp. Stn. 26, 115-164 (1984).

9) M. Ronaghi: Genome Res. 11, 3-11 (2001).

10) A. Alderborn, A. Kristofferson and U. Hammerling: Genome Res. 10, 1249-1258 (2000).

11) G. Stammler, D. Strobel, M. Semar and K. Klappach: Asp. Appl. Biol. 78, 29-36 (2006).

12) Y. Araki, M. Sugihara, H. Sawada, H. Fujimoto and M. Masuko: J. Pestic. Sci. 30, 203-208 (2005).

13) C. R. Newton, A. Graham, L. E. Heptinstall, S. J. Powell, C. Summers, N. Kalsheker, J. C. Smith and A. F. Markham: Nucl. Acids Res. 17, 2503-2516 (1989). 